\title{
IMPLANTS DELIVERING BISPHOSPHONATE LOCALLY INCREASE PERIPROSTHETIC BONE DENSITY IN AN OSTEOPOROTIC SHEEP MODEL. A PILOT STUDY
}

\author{
V. A. Stadelmann 1 , O. Gauthier ${ }^{2}$, A. Terrier ${ }^{1}$, J.-M. Bouler ${ }^{2}$, D. P. Pioletti ${ }^{*}$ \\ ${ }^{1}$ Laboratory of Biomechanical Orthopedics EPFL-DAL, IBI, Ecole Polytechnique Fédérale de Lausanne, \\ Switzerland \\ ${ }^{2}$ Laboratoire de Recherche sur les Matériaux d'Intérêt Biologique INSERM 99-03, Faculté de Chirurgie Dentaire, \\ Nantes, France
}

\begin{abstract}
It is a clinical challenge to obtain a sufficient orthopaedic implant fixation in weak osteoporotic bone. When the primary implant fixation is poor, micromotions occur at the bone-implant interface, activating osteoclasts, which leads to implant loosening. Bisphosphonate can be used to prevent the osteoclastic response, but when administered systemically its bioavailability is low and the time it takes for the drug to reach the periprosthetic bone may be a limiting factor. Recent data has shown that delivering bisphosphonate locally from the implant surface could be an interesting solution. Local bisphosphonate delivery increased periprosthetic bone density, which leads to a stronger implant fixation, as demonstrated in rats by the increased implant pullout force. The aim of the present study was to verify the positive effect on periprosthetic bone remodelling of local bisphosphonate delivery in an osteoporotic sheep model. Four implants coated with zoledronate and two control implants were inserted in the femoral condyle of ovariectomized sheep for 4 weeks. The bone at the implant surface was $50 \%$ higher in the zoledronate-group compared to control group. This effect was significant up to a distance of $400 \mu \mathrm{m}$ from the implant surface. The presented results are similar to what was observed in the osteoporotic rat model, which suggest that the concept of releasing zoledronate locally from the implant to increase the implant fixation is not species specific. The results of this trial study support the claim that local zoledronate could increase the fixation of an implant in weak bone.
\end{abstract}

Keywords: orthopaedic implant, drug delivery in vivo, sheep, bisphosphonate coating

*Address for correspondence:

Dominique P. Pioletti

Laboratory of Biomechanical Orthopedics EPFL-DAL

Bat AI - Station 15 - EPFL

CH 1015 Lausanne

Switzerland

Telephone Number: +41216938341

FAX Number: +41216938660

E-mail: dominique.pioletti@epfl.ch

\section{Introduction}

A current clinical challenge in the field of orthopaedics is to obtain a stable implant fixation in weak osteoporotic bone. The fixation of orthopaedic implants in bone relies strongly upon the initial stability of the implant. When the initial stability is not achieved, micromotions occur at the bone implant interface (Mandell et al., 2004; Ramaniraka et al., 2000). The micromotions then activate an osteoclastic response (Stadelmann et al., 2008), which results in periprosthetic osteolysis and later implant migration and wear (Karrholm et al., 1994). Both particulate formation from implant wear and implant migration have been shown to be associated with increased implant failure rate (Clarke et al., 1992; Horikoshi et al., 1994). In the case of osteoporotic patients, this early phase is particularly delicate as the bone is already weak at the time of surgery. In this case, the resorption of a small amount of bone near the implant may induce a dramatic decrease in early fixation, accelerating the failure process.

Bisphosphonate can be used to reduce periprosthetic osteolysis allowing orthopaedic implants to achieve a stronger primary fixation (Hilding et al., 2000). Bisphosphonate molecules inhibit osteoclastic activity, and therefore are widely used to treat patients with osteoporosis (Bone et al., 2004; Fleisch, 2002). However, when administered orally, the bioavailability of bisphosphonate is generally very low, and its local delivery can be further delayed in regions of the skeleton with low blood perfusion, for example the femoral neck. Recent clinical studies have shown that systemic bisphosphonate treatment following prosthesis implantation reduced periprosthetic bone loss only after 3 months (Nehme et al., 2003; Venesmaa et al., 2001b), while significant bone loss arises during this initial period of 3 months (Venesmaa et al., 2001a). A solution to accelerate the local availability of bisphosphonate at the implant location is to deliver the drug locally. This insures the immediate presence of drug molecules at the implant location regardless of the local blood perfusion.

Implants with local delivery of bisphosphonate have been studied previously in small animal models and the results are generally encouraging: In rats, hydroxyapatite coated implants releasing zoledronate increased periprosthetic bone density and the pullout force (Peter et al., 2005); fibrin coated cortical screws releasing ibandronate and pamidronate increased the pullout force (Wermelin et al., 2007). Moreover, in dog ulna, Tanzer et al. showed that local elution of zoledronate can cause 
substantial bone augmentation around and within porous tantalum implants (Tanzer et al., 2005). Concerning the osteoporotic bone case, hydroxapatite coated implants releasing zoledronate increased pullout force and periprosthetic bone density, compared to control implants in osteoporotic rats (Peter et al., 2006).

Many differences, such as mineral density, healing capacity or the response to mechanical stimuli, exist in the bone metabolism of small animals when compared to that of humans (Egermann et al., 2005; Holy et al., 2000). Therefore it is questionable to extrapolate the in vivo results of small animals into the specific clinical situation of osteoporotic patients without pre-clinical tests in a large animal (Buma et al., 2004). To our knowledge, no data exists concerning local delivery of bisphophonate to increase fixation strength of an implant in a large osteoporotic animal model.

Therefore, the aim of the present study was to verify the efficacy of local bisphosphonate delivery to increase the periprosthetic bone density in an osteoporotic sheep model (Turner, 2002).

\section{Materials and Methods}

\section{Implants}

Six Titanium alloy (TA6V) cylinders (diameter $3 \mathrm{~mm}$; length $5 \mathrm{~mm}$ ) were plasma-coated with hydroxyapatite (thickness: $20 \mu \mathrm{m}$; crystallinity index 62\%). Two samples were used as controls, while the remaining 4 samples were soaked for $48 \mathrm{~h}$ in $5 \mathrm{ml}$ ultrapure water solutions of 2.25 $10^{-5} \mathrm{~mol} \mathrm{~L}^{-1}$ of Zoledronate (1-hydroxy-2-[(1H-imidazole1-yl)ethylidene] 1-bisphosphonic acid disodium salt) supplied by Novartis Pharmaceuticals AG, Basel, Switzerland. The amount of zoledronate loaded onto the implants was calculated to be $2.1 \mu \mathrm{g}$ for each implant (Josse et al., 2004).

\section{Animals and surgical procedures}

Animal handling and surgical procedures were conducted according to the European Community Guidelines for the care and use of laboratory animals (DE 86/609/CEE) and approved by the local ethical committee at the Nantes Veterinary School. Three adult female vendeen sheep with an average body weight of $55 \mathrm{~kg}$ were used in this study. Six months prior to the study, animals had been neutered by ovariectomy to induce osteoporosis. Subsequent bone changes were investigated on iliac crest bone biopsies. A control biopsy was harvested on the day of ovariectomy and was compared with a bone sample from the contralateral iliac crest harvested 6 months later on the day of implantation. Changes in the microarchitecture of iliac crest biopsies were investigated through 3D microtomography analysis.

The tested cylinders were implanted bilaterally for 4 weeks at the distal femoral end of the 3 mature female sheep. The first animal had two control implants. The second and third animals had two zoledronate coated implants. After 2 weeks of acclimatization, general anaesthesia was induced using an intravenous injection of
$4 \mathrm{mg} / \mathrm{kg}$ of propofol (Rapinovet ${ }^{\circledR}$, Schering-Plough, Levallois-Perret, France) and $0.1 \mathrm{mg} / \mathrm{kg}$ of diazepam (Valium $^{\circledR}$, Roche, Neuilly-sur-Seine, France). Anaesthesia was maintained for surgery with a gas mixture of isoflurane (1.5\%), and oxygen (98.5\%). A single dose of morphine $(0.5 \mathrm{mg} / \mathrm{kg})$ was injected subcutaneously at the beginning of the surgery as an analgesic. After shaving and disinfection (Vetedine ${ }^{\circledR}$, Vetoquinol, Lure, France) of the knee, a stifle arthrotomy was performed to expose the distal lateral condyle of the femur.

A cylindrical osseous defect $(3 \mathrm{~mm}$ in diameter and 6 mm length) was created on the distal femoral epiphysis using a motor-driven drill (Aesculap, Tuttlingen, Germany). After saline irrigation, the osseous cavity was carefully dried and filled with the coated cylinder. The joint capsule was closed with non-absorbable sutures (Prolene ${ }^{\circledR} 2-0$, Ethicon, Issy Les Moulineux, France). The subcutaneous tissues and skin were closed in different layers using absorbable sutures (Polysorb ${ }^{\circledR}$ 2-0, TycoHealthcare, Elancourt, France). Finally, the surgical wound was covered with an adhesive bandage. Both hind limbs were operated, giving 2 tested implants per animal. At the end of surgery, animals received an injection of meloxicam to complete analgesia (Métacam Bovin ${ }^{\circledR}$, Boehringer Ingelheim, Germany) but did not receive any postoperative antibiotics. The procedure was repeated on the contra lateral side.

After 4 weeks, general anaesthesia was induced by a mixed injection of ketamine (Imalgène ${ }^{\circledR} 1000$, Merial, Lyon, France) and xylazine (Rompun ${ }^{\circledR}$, Bayer, Puteaux, France) and the animals were euthanatized by intravenous injection of $20 \mathrm{ml}$ of pentobarbital (Doléthal ${ }^{\circledR}$, Vétoquinol) through a catheter placed into the jugular vein. The femoral extremities were then dissected from the surrounding soft tissues and immediately placed in a 10 $\%$ neutral formol solution.

\section{Preparation for imaging}

The femoral distal ends were then immediately dissected, fixed in glutaraldehyde solution, and stored in a $4 \%$ paraformaldehyde, $0.1 \%$ glutaraldehyde in $0.08 \mathrm{M}$ cacodylate buffer. Using a handsaw, the condyle was sawed off $1 \mathrm{~cm}$ above the implant. The sample was dehydrated in a series of alcohol solutions. The first impregnation step was to soak the sample in a mixture of 50\% alcohol 1008 and 50\% methyl methacrylate MMA (Fluka Chemika, Sigma Aldrich Chemie Gmbh, Steinheim, Germany) during 24 hours. The second impregnation step was to soak the sample in pure MMA during 24 hours. The first inclusion step was to soak the dehydrated sample during 2 hours under vacuum in a solution containing 90\% MMA, 10\% dibutylphtalate (Fluka Chemika) and 1\% benzoyl peroxide (Fluka Chemika). The sample was then removed from the solution and soaked in the same solution but enhanced by a polymerization activator (N,N-dimethylptoluidine) (Fluka Chemika). The polymerization took place at $-20^{\circ} \mathrm{C}$ and was complete after 48 hours. Two to four slices of $300 \mu \mathrm{m}$ thick were cut from each sample, using a Microtome 1600 (Leica, Nussloch, Germany) diamond saw. The cutting plane was perpendicular to the implant. 


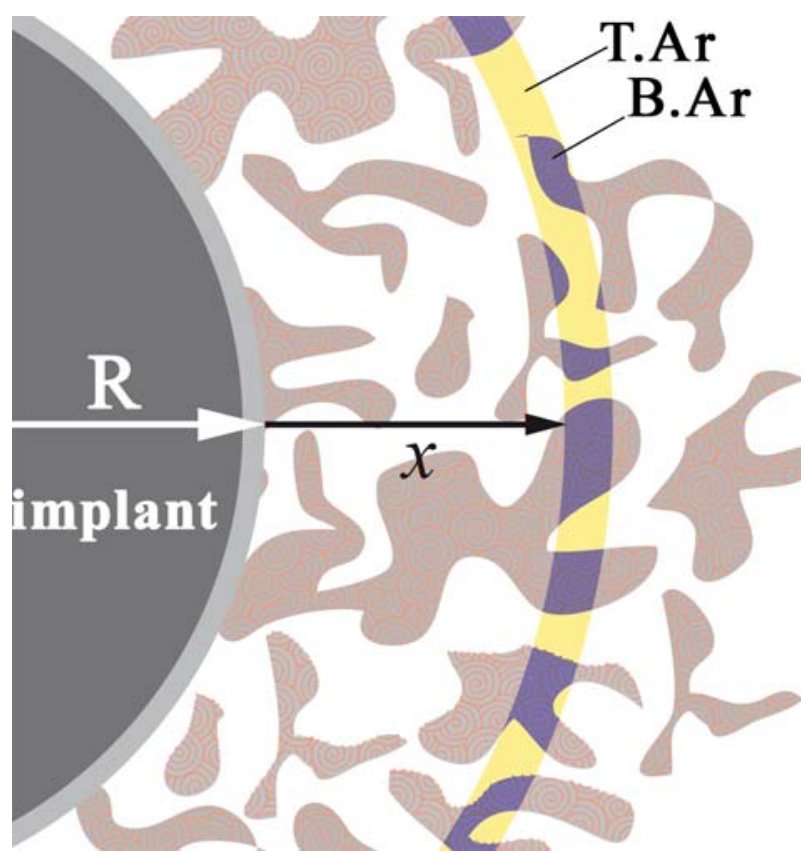

Figure 1: Schematic of the method used to determine the bone surface fraction profile. At a distance $x$ from the coating surface, a region of interest (ROI) was defined as an annulus of $20 \mu \mathrm{m}$ thickness co-centred with the implant of radius $R+x$, where $R$ is the implant radius. Then the number of bone pixels inside the ROI (blue pixels) was divided by the total number of pixels in the ROI (blue+yellow pixels). The distance $x$ was incremented from 0 to $1 \mathrm{~mm}$ in steps of $20 \mu \mathrm{m}$.

\section{Scanning Electron Microscopy}

Slices were carbon-coated and observed using a JEOL JSM 6300 scanning electron microscope (SEM) (JEOL, Tokyo, Japan) using the backscattered electron detector, allowing mineralized bone to be distinguished from soft tissue.

Then, SEM images were used to measure the bone density as a function of the distance from the coating. The implant surface and trabecular bone regions were defined manually on each image. The implant centre and radius were then calculated by least square fitting of a circle onto the implant surface. A threshold was applied to the image in order to distinguish bone from other tissues: pixels with a gray level between 0 and 62 were considered as calcified bone, while those with a gray level from 63 to 255 were considered as other tissues. We defined successive regions of interests inside the trabecular bone in the form of series of ten $20 \mu \mathrm{m}$ thick arcs co-centred with the implant. In each
Table 1: Number of animals, implants and slices per group

\begin{tabular}{|l|l|l|}
\hline & Control & Zoledronate \\
\hline Sheep & 1 & 2 \\
\hline Implants & 2 & 4 \\
\hline Slices & 6 & 13 \\
\hline
\end{tabular}

arc, the number of bone pixels was counted and the bone surface fraction (B.Ar/T.Ar) was defined as bone pixels divided by total pixels in the arc, using custom algorithms developed with Image Processing for Mathematica (Fig. $1)$.

\section{Statistics}

The number of slices per group was accounted for as repetition of the density measurement of the same group. Student $t$-test was used to determine the statistical significance of the results. Wilcoxon test was used to identify the significant changes of microstructural properties in the iliac crest biopsies.

\section{Results}

A total of 19 slices ( 6 control, 13 zoledronate-loaded) were processed (Table 1).

\section{Osteoporosis induction}

Significant microstructural evolutions were measured on the iliac crest biopsies (Fig. 2). The bone volume fraction (BV/TV) decreased by $30 \%$ at six months postovariectomy. While trabecular thickness (Tb.Th), trabecular number (Tb.N) and trabecular separation (Tb.Sp) decreased by $11 \%, 19 \%$, and increased by $14 \%$ respectively; the structural model index (SMI) was not significantly affected (Table 2 ).

\section{Implant integration}

The implant integration was verified qualitatively during backscattered electron microscopy imaging. We observed homogenous bone-implant contact as well as new bone formation along the coating surface. Lacunae were observed in the bone speckles growing from the coating. Different levels of mineralization were observed in the newly formed bone. The coating was partially resorbed, and new bone was observed in the resorption zones (fig. $3)$.

Table 2: Microstructure data of iliac crest biopsies obtained before ovariectomy (Control) and the day of implantation $(\mathrm{OVX})$, data as Mean $\pm \mathrm{SD}$. The evolution column shows significant changes $(p<0.05)$. The relative evolution of bone architecture parameters emphasises osteoporosis induction.

\begin{tabular}{|l|l|l|l|}
\hline & Control & OVX & Evolution (\%) \\
\hline BV/TV (\%) & $19.0 \pm 3.3$ & $13.3 \pm 1.3$ & -30 \\
\hline Tb.Th $(\boldsymbol{\mu m})$ & $144.1 \pm 15.8$ & $128.0 \pm 11.1$ & -11 \\
\hline Tb.N $(\mathbf{1 0} / \boldsymbol{\mu} \mathbf{m})$ & $1.32 \pm 0.14$ & $1.07 \pm 0.15$ & -19 \\
\hline Tb.Sp $(\boldsymbol{\mu m})$ & $683 \pm 56$ & $783 \pm 66$ & +14 \\
\hline SMI & $0.86 \pm 0.23$ & $0.90 \pm 0.18$ & \\
\hline
\end{tabular}




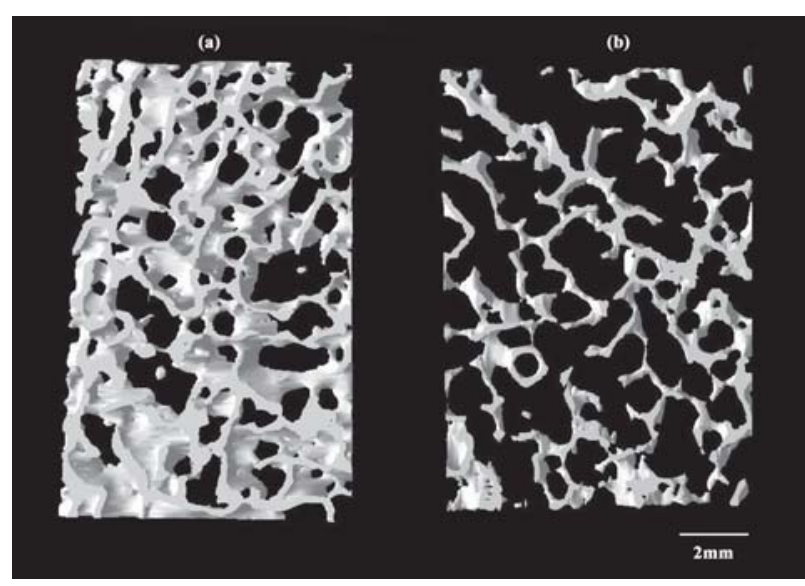

Figure 2: Three-dimensional microtomographic description of iliac crest biopsies microarchitecture (a) before ovariectomy and (b) 6 months after ovariectomy. The difference illustrates the induction of osteoporosis.

\section{Bone surface fraction}

The bone surface fraction (B.Ar/T.Ar) in a $20 \mu \mathrm{m}$-thick layer around the implant was 50\% higher in the zoledronate group compared to the control group (B.Ar/ T.Ar $=0.45 \pm 0.08$ for the zoledronate group, $0.30 \pm 0.07$ for the control group, $p<0.05)$. B.Ar/T.Ar of the zoledronate group decreased from $0.45 \pm 0.08$ at the coating surface to $0.30 \pm 0.05$ at $800 \mu \mathrm{m}$ from the coating, while the profile of the control group was almost constant (figure 4a). The difference between B.Ar/T.Ar of the zoledronate group and the control group was significant up to $400 \mu \mathrm{m}$ from the coating (figure $4 \mathrm{~b}$ ). The total bone area (B.Ar) in $400 \mu \mathrm{m}$-thick layer around the implant was $10 \%$ greater in zoledronate group compared to control group $(p<0.05)$ (fig.4c).

\section{Discussion}

Implants locally delivering bisphosphonate have been shown to increase periprosthetic bone density and pullout forces in previous studies using rat models (Kajiwara et al., 2005; Wermelin et al., 2007). However, the bone metabolism of healing and remodelling in rats is different in humans (Buma et al., 2004; Egermann et al., 2005). Therefore, a large animal study was necessary to validate these results for later applications to human patients with osteoporotic bone. In this study, our aim was to use the osteoporotic sheep model to verify the efficacy of locally delivering zoledronate from an orthopaedic implant to increase the periprosthetic bone density.

Our results showed that B.Ar/T.Ar in a $20 \mu \mathrm{m}$ layer was increased by $50 \%$ in the locally delivered-zoledronate group compared to the control group in osteoporotic sheep. The effect of local delivery of zoledronate on B.Ar/T.Ar was significant up to $400 \mu \mathrm{m}$ distance from the implant. The mean B.Ar/T.Ar in the $400 \mu \mathrm{m}$ region around the implant was increased by $10 \%$ in the zoledronate-group compared to the control group.
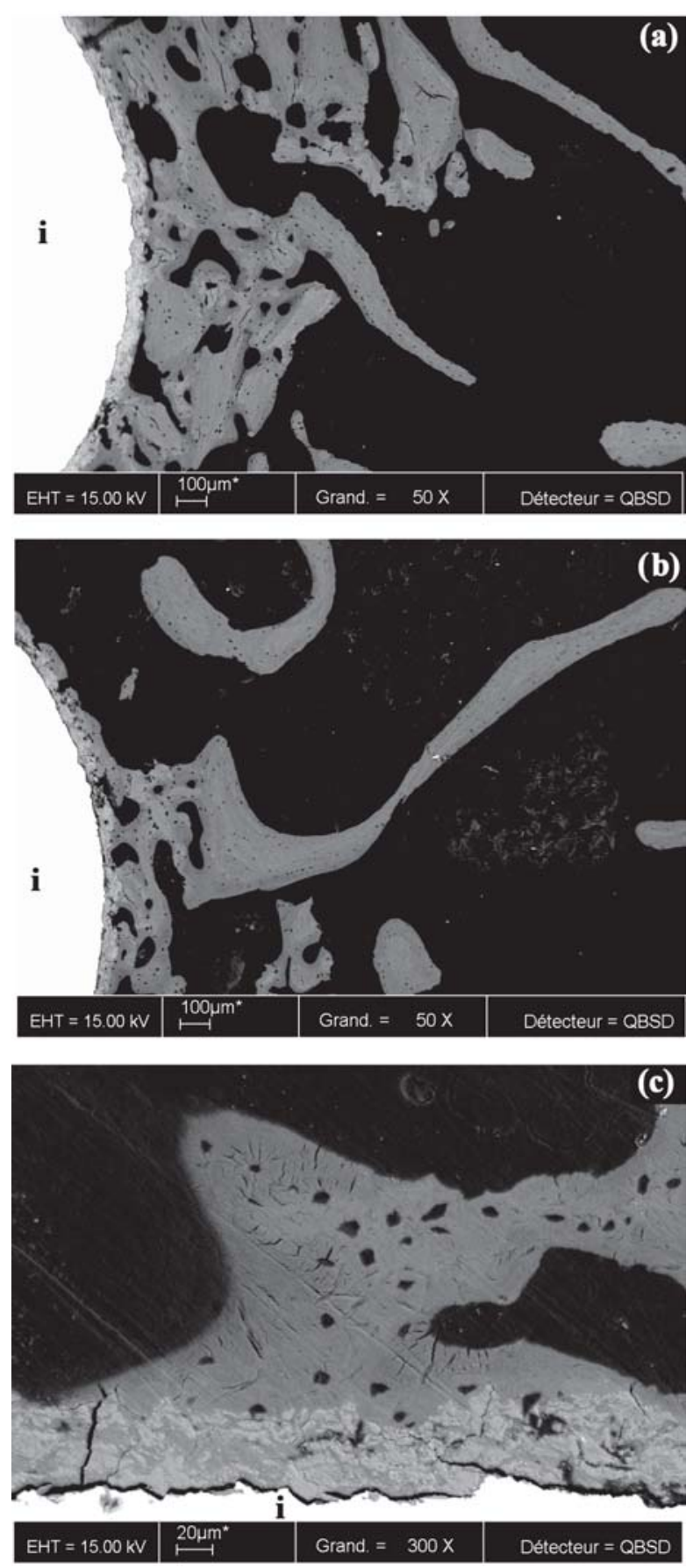

Figure 3: SEM pictures of three slices of implants; (a) Local bone structure of a condyle implanted with an HA-coated implant (i) containing $2.1 \mu \mathrm{g}$ zoledronate; (b) Local bone structure of a condyle implanted with a control implant (i); (c) Details of the osseointegration of an zoledronate-implant (i) shows bone growth into resorbed spaces of the coating. Osseointergation in control implants was qualitatively similar.

The implant and dose of zoledronate used in the sheep condyles are identical to those implanted for three weeks in previous rat and OVX rat models (Peter et al., 2005, 2006). The experimental timeline for the sheep was chosen to be four weeks as to compensate for the possibility of a slower remodelling rate in larger animals. When the results of these different models were compared (Table 2), we 
(a)

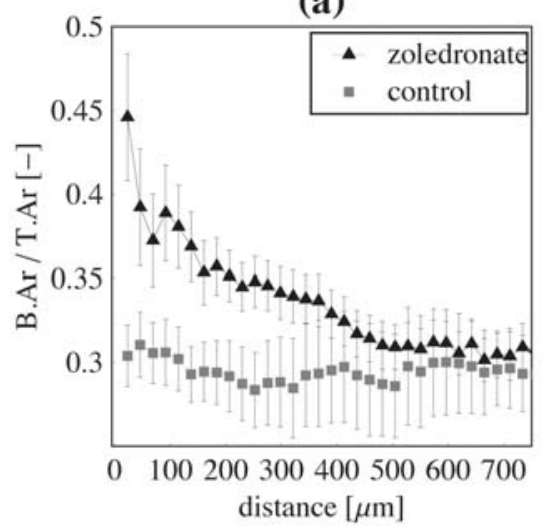

(b)

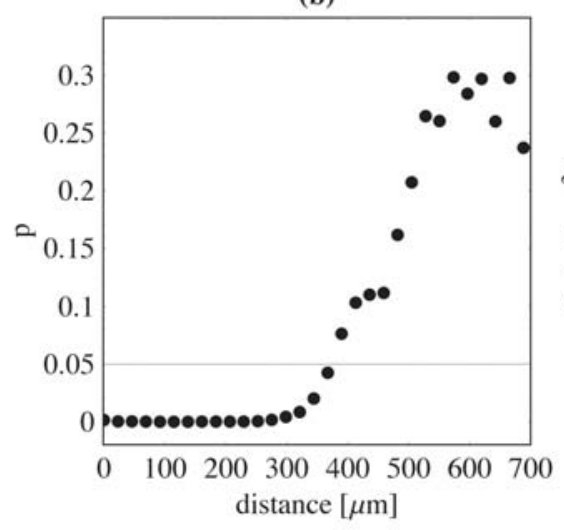

(c)

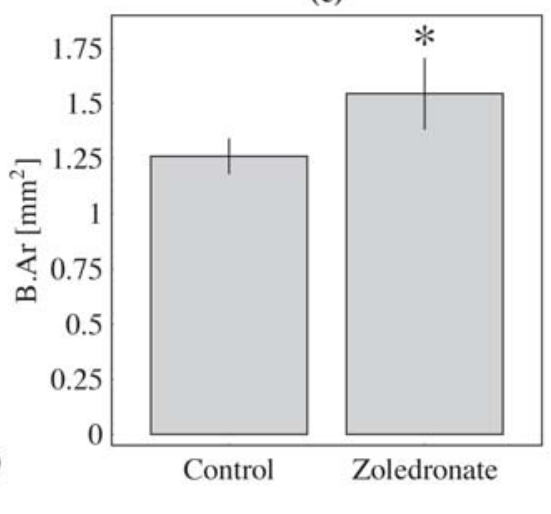

Figure 4: (a) Bone surface fraction (Mean \pm SEM) as a function of the distance from the implant coating. (b) Student $t$-test's $p$-value of B.Ar/T.Ar comparison between zoledronate-group and control-group as a function of the distance from the coating: the effect of local zoledronate is significant up to $400 \mu \mathrm{m}$ from the coating. (c) Total periprosthetic bone surface in a $400 \mu \mathrm{m}$ thick layer around the implant for zoledronate group and control group (Mean $\pm \mathrm{SD}$, *: $p<0.05$, compared to control, SD were calculated from the number of slices per group which were accounted for as repetition of the density measurement of the same group).

observed: In non-osteoporotic rats, zoledronate coated implants induced an increase of $43 \%$ of B.Ar/T.Ar at the implant surface, while in osteoporotic rats the increase was $20 \%$ at 3 weeks post-surgery. In the present osteoporotic sheep model, at 4 weeks post-surgery, we observed an increase of $50 \%$, which is significantly greater than the effect in rats. Moreover, the distance from the implant over which the effect of zoledronate is significant is five times greater in osteoporotic sheep than in osteoporotic rats.

The observed difference cannot be explained simply with this data. It can be related to prolongation of one week in the post-surgery delay, to an enhanced reaction of sheep bone cells to zoledronate, or to the initial difference in bone density. Despite the questions that remain unanswered, these results show that a small dose of zoledronate delivered locally in osteoporotic sheep bone efficiently increases periprosthetic bone density in a way similar to what was previously observed in rats.

This result is concordant with the very recent study of Goodship et al., in which intravenous administration of zoledronate pre- peri- and postsurgery reduced periprosthetic cortical osteopenia in a sheep model of hip replacement (Goodship et al., 2008). Therefore, zoledronate treatments seem to have a beneficial action on periprosthetic bone, cortical or trabecular.

The goal of local bisphosphonate release is to increase the implant fixation strength, but a complete pullout study would have required supplementary animals. Pullout force is mainly influenced by bone density in a thin layer of bone, extending $20 \mu \mathrm{m}$ radially from the implant (Peter et al., 2005). In osteoporotic rats, an increase of $20 \%$ of bone volume fraction in the $20 \mu \mathrm{m}$ layer induced nearly a $100 \%$ increase in pullout force $(175 \pm 70 \mathrm{~N}$ with $2.1 \mu \mathrm{g}$ compared to $90 \pm 30 \mathrm{~N}$ for controls). However, the exact effect on pullout force in the sheep model cannot be calculated from rat models, as the scale of bone trabeculae and the bone density are very different in these species. But, with more than 2-fold increase in bone volume fraction in the $20 \mu \mathrm{m}$ layer, it is likely that an increase in pullout force would be observed as well in the present study.

Zoledronate, like other bisphosphonates, has been shown to limit bone loss in patients with osteoporosis (Glatt, 2001), while also inducing a beneficial impact on microarchitectural properties of trabecular bone (Poole et al., 2007; Recker et al., 2008). In the present study we did not assess other microarchitectural properties of periprosthetic bone than B.Ar/T.Ar. However, some of these properties, such as the bone volume fraction are mathematically linked to B.Ar/T.Ar (Parfitt et al., 1987; Revell, 1983).

\section{Clinical relevance of the study}

The clinical aim of coating orthopaedic implants with zoledronate is to improve the fixation of orthopaedic implants in patients with weak bone. Benefits of zoledronate local delivery were previously observed in osteoporotic rats. The present study further extended these results to a large animal model. The measured increase of

Table 3: Comparison of the effect of $2.1 \mu \mathrm{g}$ zoledronate / implant versus control on periprosthetic B.Ar/T.Ar in a $20 \mu \mathrm{m}$ layer, and distance of the effect from the implant. Rats and osteoporotic rats data adapted from (Peter et al., 2005) and (Peter et al., 2006), respectively.

\begin{tabular}{|l|l|l|l|l|}
\hline & $\begin{array}{l}\text { B.Ar/T.Ar } \\
\text { Control }\end{array}$ & $\begin{array}{l}\text { B.Ar/T.Ar } \\
\text { Zoledronate }\end{array}$ & $\begin{array}{l}\text { Relative } \\
\text { Increase }\end{array}$ & $\begin{array}{l}\text { Distance of } \\
\text { the effect }\end{array}$ \\
\hline Rats & $0.48 \pm 0.04$ & $0.69 \pm 0.03$ & $43 \%$ & $250 \mu \mathrm{m}$ \\
\hline OVX rats & $0.46 \pm 0.03$ & $0.55 \pm 0.03$ & $20 \%$ & $70 \mu \mathrm{m}$ \\
\hline OVX sheep & $0.30 \pm 0.07$ & $0.45 \pm 0.08$ & $50 \%$ & $400 \mu \mathrm{m}$ \\
\hline
\end{tabular}


periprosthetic bone density supported that local zoledronate delivery significantly improves the implant fixation in osteoporotic sheep.

To further validate the use of implants with local zoledronate delivery, the next set of experiments should be performed with full load bearing implants to quantify the combined effects of mechanical stimulus and zoledronate release to the response of periprosthetic bone.

\section{Acknowledgements}

Project no. 04-P2 was supported by the AO Research Fund of the AO Foundation, (Davos, Switzerland). We thank Novartis Pharma Research (Basel, Switzerland) for a generous gift of Zoledronate. We thank Bruno Bujoli, Sophie Salice and Paul Pilet for technical assistance and Tyler Thacher for English editing.

\section{References}

Bone HG, Hosking D, Devogelaer JP, Tucci JR, Emkey RD, Tonino RP, Rodriguez-Portales JA, Downs RW, Gupta J, Santora AC, Liberman UA (2004) Ten years' experience with alendronate for osteoporosis in postmenopausal women. N Engl J Med 350:1189-1199.

Buma P, Schreurs W, Verdonschot N (2004) Skeletal tissue engineering - from in vitro studies to large animal models. Biomaterials 25:1487-1495.

Clarke IC, Campbell P, Kossovsky N (1992) Debrismediated osteolysis-A cascade phenomenom invovling motion, wear, particulates, macrophage induction, and bone lysis. In: St. John KR (ed). Particulate debris from medical implants: mechanisms of formation and biological consequences, ASTM STP 1144. Philadelphia, American Society for Testing and materials, 7-26.

Egermann M, Goldhahn J, Schneider E (2005) Animal models for fracture treatment in osteoporosis. Osteoporos Int 16 (suppl 2): S129-S138.

Fleisch H (2002) Development of bisphosphonates. Breast Cancer Res 4:30-34.

Glatt M (2001) The bisphosphonate zoledronate prevents vertebral bone loss in mature estrogen-deficient rats as assessed by micro-computed tomography. Eur Cell Mater 1:18-26.

Goodship AE, Blunn GW, Green J, Coathup MJ (2008) Prevention of strain-related osteopenia in aseptic loosening of hip prostheses using perioperative bisphosphonate. J Orthop Res 26:693-703.

Hilding M, Ryd L, Toksvig-Larsen S, Aspenberg P (2000) Clodronate prevents prosthetic migration: a randomized radiostereometric study of 50 total knee patients. Acta Orthop Scand 71:553-557.

Holy C, Fialkov J, Shoichet M, Davies J (2000) In vivo models for bone tissue-engineering constructs. In Davies $\mathrm{J}$ (ed). Bone engineering. Toronto, em squared inc, 496504.

Horikoshi M, Macaulay W, Booth RE, Crossett LS, Rubash HE (1994) Comparison of interface membranes obtained from failed cemented and cementless hip and knee prostheses. Clin Orthop Relat Res 309:69-87.
Josse S, Faucheux C, Soueidan A, Grimandi G, Massiot D, Alonso B, Janvier P, Laib S, Gauthier O, Daculsi G, Guicheux J, Bujoli B, Bouler JM (2004) Chemically modified calcium phosphates as novel materials for bisphosphonate delivery. Adv Mat 16:1423-1427.

Kajiwara H, Yamaza T, Yoshinari M, Goto T, Iyama S, Atsuta I, Kido MA, Tanaka T (2005) The bisphosphonate pamidronate on the surface of titanium stimulates bone formation around tibial implants in rats. Biomaterials 26:581-587.

Karrholm J, Borssen B, Lowenhielm G, Snorrason F (1994) Does early micromotion of femoral stem prostheses matter? 4-7-year stereoradiographic follow-up of 84 cemented prostheses. J Bone Joint Surg Br 76:912-917.

Mandell JA, Carter DR, Goodman SB, Schurman DJ, Beaupre GS (2004) A conical-collared intramedullary stem can improve stress transfer and limit micromotion. Clin Biomech (Bristol, Avon) 19:695-703.

Nehme A, Maalouf G, Tricoire JL, Giordano G, Chiron P, Puget J (2003) Effect of alendronate on periprosthetic bone loss after cemented primary total hip arthroplasty: a prospective randomized study. Rev Chir Orthop Rep App Moteur 89:593-598.

Parfitt AM, Drezner MK, Glorieux FH, Kanis JA, Malluche H, Meunier PJ, Ott SM, Recker RR (1987) Bone histomorphometry: standardization of nomenclature, symbols, and units. Report of the ASBMR Histomorphometry Nomenclature Committee. J Bone Miner Res 2:595-610.

Peter B, Pioletti DP, Laib S, Bujoli B, Pilet P, Janvier P, Guicheux J, Zambelli PY, Bouler JM, Gauthier O (2005) Calcium phosphate drug delivery system: influence of local zoledronate release on bone implant osteointegration. Bone 36:52-60.

Peter B, Gauthier O, Laib S, Bujoli B, Guicheux J, Janvier P, van Lenthe GH, Muller R, Zambelli PY, Bouler JM, Pioletti DP (2006) Local delivery of bisphosphonate from coated orthopedic implants increases implants mechanical stability in osteoporotic rats. J Biomed Mater Res A 76:133-143.

Poole KES, Loveridge N, Vedi S, Compston JE, Reeve J (2007) The effects of zoledronate on iliac bone remodelling in stroke patients. J Bone Miner Res 22:11381139.

Ramaniraka NA, Rakotomanana LR, Leyvraz PF (2000) The fixation of the cemented femoral component. Effects of stem stiffness, cement thickness and roughness of the cement-bone surface. J Bone Joint Surg Br 82:297303.

Recker RR, Delmas PD, Halse J, Reid IR, Boonen S, Garcia-Hernandez PA, Supronik J, Lewiecki EM, Ochoa L, Miller P, Hu H, Mesenbrink P, Hartl F, Gasser J, Eriksen EF (2008) Effects of intravenous zoledronic acid once yearly on bone remodeling and bone structure. J Bone MinerRes 23:6-16.

Revell PA (1983) Histomorphometry of Bone. J Clin Path 36:1323-1331.

Stadelmann VA, Terrier A, Pioletti DP (2008) Microstimulation at the bone-implant interface upregulates osteoclast activation pathways. Bone 42:358 - 364 . 
Tanzer M, Karabasz D, Krygier JJ, Cohen R, Bobyn JD (2005) Bone augmentation around and within porous implants by local bisphosphonate elution. Clin Orthop Rel Res 441:30-39.

Turner AS (2002) The sheep as a model for osteoporosis in humans. Vet J 163:232-239.

Venesmaa PK, Kroger HPJ, Miettinen HJA, Jurvelin JS, Suomalainen OT, Alhava EM (2001a) Monitoring of periprosthetic BMD after uncemented total hip arthroplasty with dual-energy X-ray absorptiometry - a 3-year followup study. J Bone Miner Res 16:1056-1061.

Venesmaa PK, Kroger HPJ, Miettinen HJA, Jurvelin JS, Suomalainen OT, Alhava EM (2001b) Alendronate reduces periprosthetic bone loss after uncemented primary total hip arthroplasty: A prospective randomized study. J Bone Miner Res 16:2126-2131.

Wermelin K, Tengvall P, Aspenberg P (2007) Surfacebound bisphosphonates enhance screw fixation in rats increasing effect up to 8 weeks after insertion. Acta Orthopaedica 78:385-392.

\section{Discussion with Reviewers}

J. Green: In the absence of extensive clinical data, the relative practical benefits of local versus systemic bisphosphonate delivery are still debatable. Whilst local delivery from a coated implant may reduce the risk of side effects, a patient requiring an implant is likely to have osteoporosis at other sites and would thus benefit from systemic drug exposure. Moreover, after a surgical intervention to implant a prosthesis, the surrounding bone is highly active and shows enhanced bisphosphonate uptake, calling into question the need for local delivery from coated implants.

Authors: Some patients requiring orthopaedic implants are likely to have osteoporosis. Regarding these patients: in cases of undiagnosed and untreated disease, a zoledronate-coated implant would certainly offer benefits compared to uncoated implants, as indicated by the present pilot study. In cases of patients already treated with bisphosphonate, there is no experimental evidence that zoledronate-coating would provide a better fixation than a systemic administration. However, while zoledronatecoating provides an immediate release of a very small amount of drug at the desired location (which in this case is independent of the rate of activity of the surrounding bone), systemic treatment provides a continuous drug uptake on a long-term basis. Thus, the optimal implant fixation in patients with osteoporosis may be obtained by a combined approach of local and systemic treatment, rather than one or the other, taking advantages of both approaches. However, this hypothesis has yet to be demonstrated experimentally.

D. Little: This small paper suggests the possibility that local bisphosphonates can improve osseointegration of implants. Do authors have any estimate on the duration of such a positive effect?

Authors: Our objective was to obtain an increase of fixation at short-term. Indeed, clinical data suggests that a good short-term implant fixation is generally followed by a strong long-term fixation, when compared to implant with early loss of fixation. Based on these results, we believe that the benefit observed after 4 weeks should last for much longer. But, the duration of the beneficial effect depends on many factors such as the mechanical environment and the rate of elimination of the drug, thus the exact duration remains to be determined experimentally.

R.G. Richards: The reduced bone volume / trabecular volume is taken as an osteoporotic model of osteoporosis. Is this really a model of osteoporosis or osteopaenia? Do the authors think that any sheep model is actually a realistic model of osteoporosis or more of osteopaenia?

Authors: To be exact the presented data is a model of severe osteopaenia. There are actually no animal models that realistically reflect the human condition of osteoporosis. However, to our knowledge the OVX sheep model is the best model available to study orthopaedic applications in osteoporotic bone (see Turner, 2002).

J. Green: As bone loss in the ovine osteoporosis model can be influenced by breed, season, diet etc, the omission of any data to confirm the extent of the osteopaenia/ osteoporosis in these 3 animals is a concern. This could have been partially addressed by using each animal as its own control with a zoledronate coated implant in one femur and an uncoated control implant on the contra-lateral side - I doubt whether there would have been any systemic drug exposure from the coated implant.

Authors: Strictly speaking the condition of these animals is osteopaenia (based on BV/TV standard deviations) but the severe bone loss of $30 \%$ detected in iliac crests biopsies suggests that this model is somewhat comparable to osteoporosis condition in some human bones. Indeed, when planning the study, our concern was that the drug could influence the contra-lateral side bone density, which is why we did not use each animal as its own control. A posteriori, the extent of the effect of the drug is very limited $(400 \mu \mathrm{m})$ and thus there would certainly be no systemic effect. This supports the own-control design in the future.

R.G. Richards: Long term bisphosphonates have been seen to increase cortical bone thickness in elderly osteoporotic patients, yet recently it has been observed that this new cortical bone is very brittle and if fractured, very difficult to repair. I assume this is because the natural remodelling is knocked out by the bisphosphonates and the osteoclasts no longer function. What effect would local bisphosphonates have on the quality of the osseointegrated bone formed?

Authors: In the case of patients not exposed systemically to bisphosphonate in parallel to the presented technique, we do not think the quality of the bone is an issue on a long-term perspective: the coated dose is available in the bone only once and is slowly retrieved from the coating and from the surrounding bone with normal metabolic processes. Therefore the remodelling of the periprosthetic bone should be reactivated after some time, and the damaged bone renewed. 